\title{
Enhancing Nitrogen Removal Performance in a Bioreactor Using Immobilized Anaerobic Ammonium Oxidation Sludge by Polyvinyl Alcohol-Sodium Alginate (PVA-SA)
}

\author{
Yifeng Lu', Lijuan Ma², Yun Liang', ${ }^{1,}$, Bei Shan4, Junjun Chang ${ }^{1 *}$ \\ ${ }^{1}$ School of Ecology and Environmental Sciences \& Yunnan Key Laboratory for Plateau Mountain Ecology \\ and Restoration of Degraded Environments, Yunnan University, Kunming, 650091, Yunnan, China \\ ${ }^{2}$ Yunnan Bossco Enviroment Protecting Technology Co. Ltd, Kunming 650000, Yunnan, China \\ ${ }^{3}$ Institute of International Rivers and Eco-security, Yunnan University, Kunming 650091, China \\ ${ }^{4}$ Kunming Institute of Landscape Science, Kunming 650224, China
}

Received: 1 April 2017

Accepted: 11 July 2017

\begin{abstract}
Anaerobic ammonium oxidation (anammox) is an efficient and promising pathway for nitrogen removal from wastewater, but its application is usually confined by the low growth rate and susceptibility to surroundings of anammox bacteria. In this study, cultured anammox sludge was immobilized using polyvinyl alcohol (PVA)-sodium alginate (SA) gel and put into a lab-scale column reactor at a packing ratio of $20 \%$, and nitrogen removal performance was evaluated at two hydraulic retention times (HRTs). Anammox was rapidly initiated in the reactor, with ammonium and nitrite removal efficiency reaching $82.3 \%$ and $84.7 \%$ after an operation period of $10 \mathrm{~d}$. Nitrogen removal efficiency declined greatly after the reduction of HRT from $24 \mathrm{~h}$ to $12 \mathrm{~h}$, but then recovered quickly, with an average TN removal rate of $84.5 \%$ and $0.43 \mathrm{~kg} \cdot \mathrm{m}^{-3} \cdot \mathrm{d}^{-1}$ achieved under the steady operational state. The immobilized anammox reactor performed significantly better and was more stable in nitrogen removal than that with anammox sludge inoculated directly, indicating the superiority of cell entrapment of anammox biomass in addition to its easy reservation. Nitrogen removal in the reactor increased after stable operation with the HRT. It has potential to apply immobilized anammox sludge entrapped by PVA-SA gel for the convenient establishment of an anammox reactor with stable and high nitrogen removal rates.
\end{abstract}

Keywords: anammox, immobilization, PVA-SA, nitrogen removal

*e-mail: changjunjun@ynu.edu.cn 


\section{Introduction}

The effective removal of nitrogen pollutants from wastewater is highly desirable for water environment protection from eutrophication and ecological degradation, and has attracted extensive attention. Conventionally, biological nitrogen removal is carried out by aerobic nitrification, which requires a sufficient supply of dissolved oxygen (DO), followed by an anoxic denitrification process usually requiring an external biodegradable organic carbon source [1-2]. Anaerobic ammonium oxidation (anammox), a new microbial nitrogen removal pathway that can directly convert $\mathrm{NH}_{4}^{+}-\mathrm{N}$ and $\mathrm{NO}_{2}^{-}-\mathrm{N}$ to $\mathrm{N}_{2}$ under anaerobic or anoxic conditions, has been put forward. It is recognized as an efficient, cost-effective, and promising process for high-rate nitrogen removal from wastewater streams especially for those containing high ammonium but low biodegradable organics [3-5]. Accordingly, the application and optimization of the anammox process has caused great interest in recent years [6-8].

Unfortunately, maintaining a sufficient amount of anammox biomass in a reactor, which is critical for its start-up and stability and high-rate nitrogen removal, is not easy and often leads to high operational and maintenance costs in practice due to the long generation time and low biomass yield as well as high sensitivity to ambient conditions of the autotrophic anammox bacteria $[4,6]$. Furthermore, the anammox sludge is vulnerable to being washed out of the reactor as a large amount of $\mathrm{N}_{2}$ gas bubbles is produced and trapped in the anammox biomass, leading to its flotation [3,9]. One viable strategy for mitigating this challenge is immobilizing the anammox biomass using the gel entrapment technique. This can provide a microenvironment and shelter favorable for cultivation of the anammox bacteria and effectively promote its retention, cell density, and resistance against toxicity, and thus facilitate its start-up and stable workings as well as easy solid-liquid separation of an anammox reactor [7, 10-12]. Cell immobilization of various microorganisms by gel entrapment has been widely applied in biological treatment processes [13-15], despite information on the employment of immobilized anammox biomass in a reactor being relatively limited. A variety of polymers have been employed as material for cell entrapment, and the complex of polyvinyl alcohol (PVA) and sodium alginate (SA) is regarded as a suitable carrier from the comprehensive considerations of cost, immobilization operation, and treatment performance as well as mechanical strength and stability [11, 15-16].

In the present study, the mixed sludge from a stably operated lab-scale anammox reactor was immobilized as gel beads using PVA-SA and then added into another labscale column reactor at a packing ratio of $20 \%$ for the treatment of synthetic wastewater containing ammonium and nitrite at two HRTs ( $24 \mathrm{~h}$ and $12 \mathrm{~h}$ ). An identical reactor inoculated with the same amount of anammox sludge directly was set as the control system. The objectives were to investigate and assess nitrogen removal performance of the immobilized anammox sludge in the reactor.

\section{Materials and Methods}

\author{
Materials
}

The seed anammox sludge used in this study was harvested from an anammox reactor that had successfully started an anammox reaction and achieved stable and high nitrogen removal efficiency in our laboratory [17]. The sludge (MLSS $3100 \mathrm{mg} / \mathrm{L}$, VSS/SS 75.5\%) was rinsed several times using phosphate buffer solution $(\mathrm{pH} 7.5$, $0.1 \mathrm{M}$ ) and normal saline to remove any impurities, and then centrifuged for $10 \mathrm{~min}$ at 5,000 rpm.

PVA-SA solution was prepared with homogeneously mixed equivalent volumes of $15 \%(\mathrm{w} / \mathrm{v})$ PVA (analytical grade, $99 \%$ saponification and $1,750 \pm 50$ polymerization degree) and $2 \%(\mathrm{w} / \mathrm{v}) \mathrm{SA}$ (analytical grade) solutions, and then heated and sterilized in an autoclave at $120^{\circ} \mathrm{C}$ for $30 \mathrm{~min}$. The concentrated sludge was slowly added into the cooled PVA-SA solution at a volumetric ratio of 1:1 and mixed homogeneously. After that, the mixture was dropped slowly into the solidification solution composed of saturated $\mathrm{H}_{3} \mathrm{BO}_{3}$ and $4 \%$ (w/v) $\mathrm{CaCl}_{2}$ by an injector. Then the formed spherical beads with 3-4 mm diameter were cured at $4^{\circ} \mathrm{C}$ for $12 \mathrm{~h}$ for cross-linking to enhance their mechanical strength $[16,18]$. Finally, these gel beads were rinsed with sterilized water until the effluent was clarified.

\section{Experimental Setup of the Reactors and the Influent Wastewater}

A column reactor made of polyvinyl chloride (PVC) at a height of $23 \mathrm{~cm}$ and internal diameter of $8 \mathrm{~cm}$ was employed as the anammox reactor in this study. Its effective working volume was $1.15 \mathrm{~L}$, with the PVA-SA gel beads put in at a volume-filling ratio of $20 \%$ (named $\mathrm{R} 1)$. The reactor was continuously operated in an upflow mode, with the synthetic wastewater dosed from the bottom at a constant flow rate by a peristaltic pump and effluent overflowed from the top after passing a plastic net ( $1 \mathrm{~mm}$ pore size) for separation of the gel beads. Agitation in the reactor was carried out by a two-blade stirrer. Another identical reactor, with the same amount of nonimmobilized anammox sludge added directly, was set as the control system (named R0). The whole experiment lasted for $50 \mathrm{~d}$, which was divided into 2 operational phases with the hydraulic retention time (HRT) set at 24 $\mathrm{h}$ during the first $25 \mathrm{~d}$ and then adjusted to $12 \mathrm{~h}$ during the following $25 \mathrm{~d}$. Both reactors were placed into a thermostatic waterbath to maintain the water temperature inside the reactor at $32 \pm 2^{\circ} \mathrm{C}$. Black-out cloth was used to prevent the reactors from the impact of light.

Synthetic wastewater was adopted by adding $\left(\mathrm{NH}_{4}\right)_{2} \mathrm{SO}_{4}$ and $\mathrm{NaNO}_{2}$ into tapwater to form an $\mathrm{NH}_{4}^{+}-\mathrm{N}$ and $\mathrm{NO}_{2}^{-}-\mathrm{N}$ concentration of $93.3 \pm 8.4$ and 
$103.8 \pm 8.5 \mathrm{mg} \cdot \mathrm{L}^{-1}$, respectively. Other trace elements were supplemented according to $[10,18]$. Influent $\mathrm{pH}$ was not intentionally controlled and ranged 7.4-7.7 during the experiment. No stripping of dissolved oxygen (DO) in the influent was carried out, partly due to deoxygenation being costly and less feasible in practical application. The water quality characteristics of the influent applied in this study were similar to those for the seed sludge reactor.

\section{Chemical and Statistical Analyses}

Inlet and outlet of R0 and R1 were routinely sampled on a daily basis and their water qualities were analyzed in the laboratory immediately. The concentrations of $\mathrm{NH}_{4}^{+}-\mathrm{N}, \mathrm{NO}_{2}^{-} \mathrm{N}$, and $\mathrm{NO}_{3}^{-}-\mathrm{N}$ were analyzed spectrophotometrically according to the standard methods [19] after filtration with $0.45 \mu \mathrm{m}$ pore size membrane. $\mathrm{DO}, \mathrm{pH}$, and oxidation reduction potential (ORP) was measured using a DO meter (Oxi 3315 SET 2, Germany), a $\mathrm{pH}$ meter (PHS-3E, INESA Company, China), and an ORP meter (DDB-303A, INESA Company, China), respectively.

Statistical analyses were performed using SPSS 17.0 software, with the difference of nitrogen removal performance between the two reactors detected by the two-sided $t$ test. Significant difference was defined when $p<0.05$.

\section{Results and Discussion}

\section{Nitrogen Removal Performance of the Immobilized} Anammox Reactor

Fig. 1 shows the time courses of nitrogen concentrations and removal efficiencies of R1 during the experiment. We found that no ammonium removal occurred on the first day, but removal efficiency increased rapidly to $82.3 \%$ on day 10 , and more than $90 \%$ of ammonium was eliminated since day 17 after the activity of immobilized anammox sludge was recovered. Nitrite removal efficiency elevated gradually from $51.8 \%$ on day 1 to $84.7 \%$ on day 10 , and more than $90 \%$ since the day 14 . A marginal amount of nitrate was produced during the first $10 \mathrm{~d}$, but its content increased gradually. Just around 10 days were taken to start up anammox successfully in R1, indicating that the anammox bacteria entrapped in the PVA-SA gel beads could be activated rapidly and the anammox process could be triggered rapidly using whole cell entrapment of anammox biomass. In contrast, the start-up of the anammox reactor using common activated sludge as seed usually requires a much longer period of around 90$120 \mathrm{~d}$ due to the slow growth rate and low biomass yield as well as stringent metabolic conditions of anammox bacteria [4, 17, 20-21], which is thus a large obstacle for its application. The removal efficiencies of nitrite and ammonium decreased sharply by half when the HRT was reduced from $24 \mathrm{~h}$ to $12 \mathrm{~h}$ on day 26 . But more than $80 \%$ removal was achieved again after an operational period of seven days, when the immobilized anammox biomass quickly adapted to the increased load, and stable high removal efficiency was maintained until the end of the experiment. A larger amount of nitrate was generated during this phase. Furthermore, no crushing of the gel beads was observed during the experiment.

For comparison, variations of nitrogen removal rates of R0 and R1 with the operation time were depicted in Fig. 2. It was seen that good $\mathrm{TN}$ removal was immediately achieved in R0 with anammox sludge inoculated directly, and the removal rate of $\mathrm{R} 0$ was obviously higher than $\mathrm{R} 1$ during the first $17 \mathrm{~d}$, with efficiency higher than $77.4 \%$. This was consistent with the result recorded by Zhu et al. [16] and mainly because mass transfer between nitrogen contaminants and anammox biomass in the PVA-SA gel beads in R1 was restricted. Nevertheless, the TN removal efficiency of R0 decreased, being contrary to R1, and just recovered to about $60 \%$ after the nitrogen loads increased in the second operational phase, probably due to that the growth and activity of anammox bacteria in R0 declined without the aid of gel carrier and a fraction of the sludge

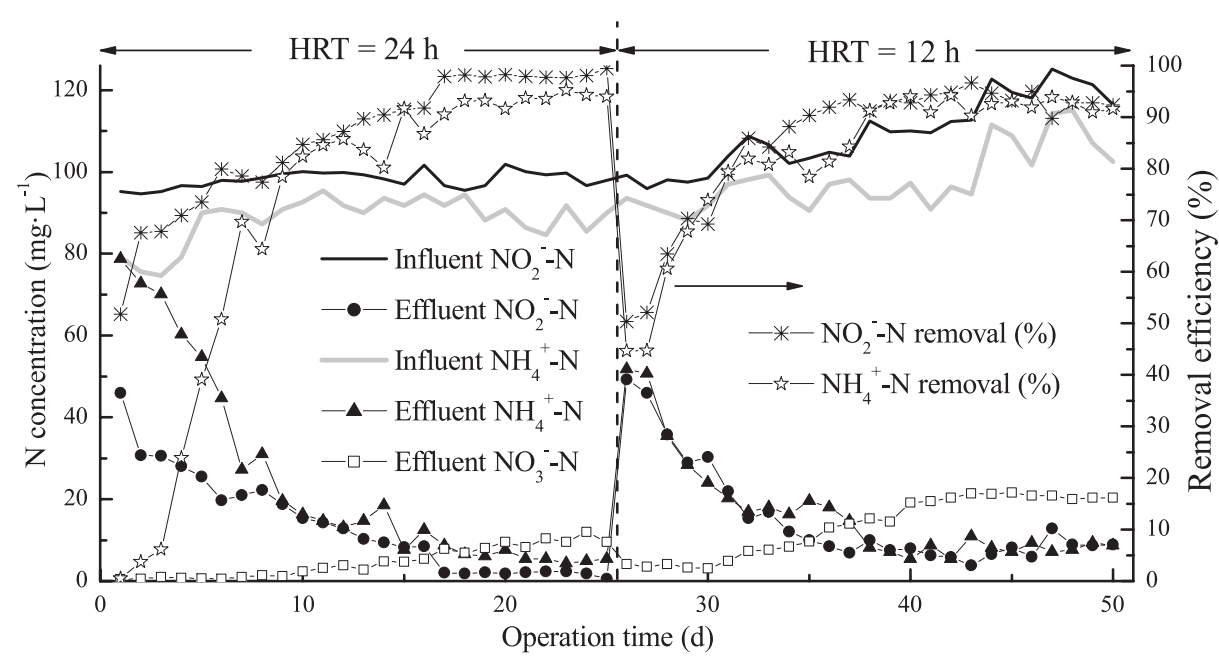

Fig. 1. Time courses of nitrogen concentrations and removal efficiencies of the reactor using the immobilized anammox sludge. 


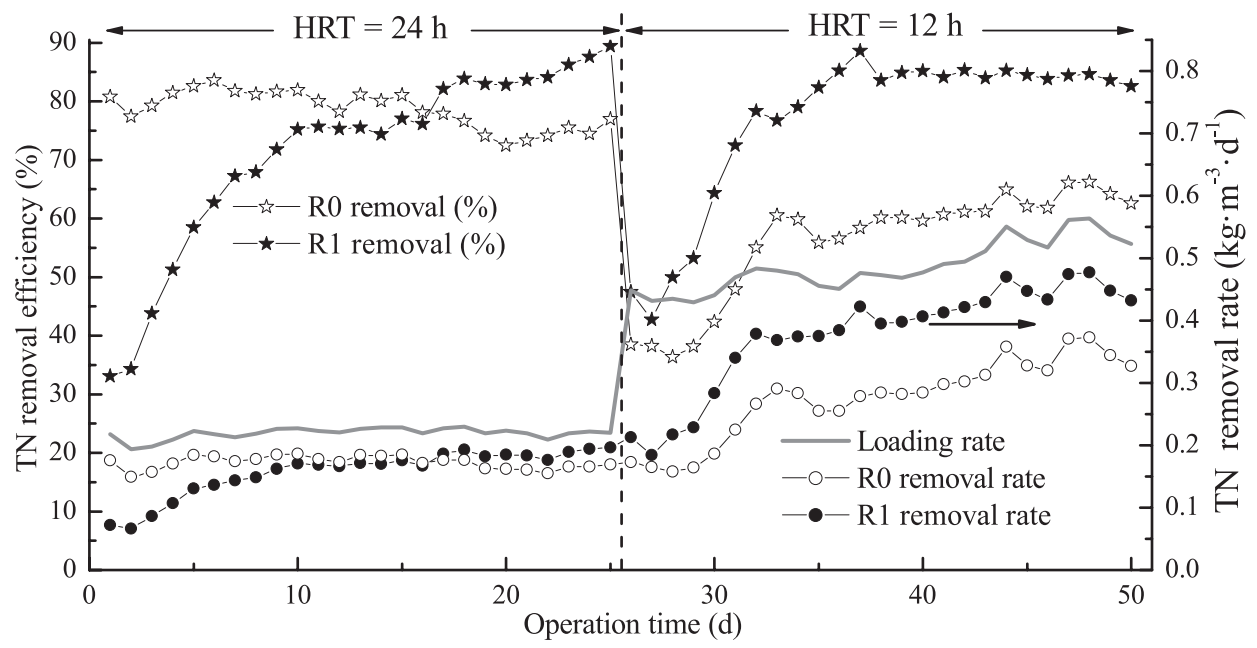

Fig. 2. Time courses of nitrogen removal rates of R1 (inoculated immobilized anammox sludge) and R0 (inoculated anammox sludge directly) during the experiment.

was washed out of the reactor. In addition, it should be noted that the obtainment and conservation of anammox sludge are greatly troublesome, despite the fact that it can start the anammox process rapidly.

Better TN removal performance was obtained in R1 since day 17 , especially in phase 2 , with the efficiency recovered within 10 days and stabilized over $83.5 \%$. $\mathrm{TN}$ volume removal rates of the reactors enhanced with the increased loading rate in phase 2 - especially for R1 after shortening the HRT - and a TN removal rate of $0.43 \pm 0.03 \mathrm{~kg} \cdot \mathrm{m}^{-3} \cdot \mathrm{d}^{-1}$ was attained by $\mathrm{R} 1$ at the loading rate of $0.50 \pm 0.03 \mathrm{~kg} \cdot \mathrm{m}^{-3} \cdot \mathrm{d}^{-1}$ with an efficiency of $84.5 \pm 1.42 \%$ since day 35 under a steady operational state (Fig. 2). A similar trend of increased nitrogen removal with increasing loading rate was also recorded in other immobilized anammox reactors [7, 10, 18, 22].

In the whole experiment, R1 performed significantly better $(p<0.05)$ and showed greater resistance to shock load than R0 in nitrogen removal capacity despite its slower anammox initiation, indicating the effectiveness of anammox biomass immobilization using PVA-SA gel. Additionally, the preservation of gel beads entrapping anammox bacteria is obviously much easier as compared with anammox sludge. The volume removal rate of 0.07-0.48 $\mathrm{kg} \mathrm{N} \cdot \mathrm{m}^{-3} \cdot \mathrm{d}^{-1}$ (mean value: $0.27 \mathrm{~kg} \cdot \mathrm{m}^{-3} \cdot \mathrm{d}^{-1}$ ) obtained by $\mathrm{R} 1$ and $0.15-0.37 \mathrm{~kg} \mathrm{~N} \cdot \mathrm{m}^{-3} \cdot \mathrm{d}^{-1}$ (mean value: $\left.0.22 \mathrm{~kg} \cdot \mathrm{m}^{-3} \cdot \mathrm{d}^{-1}\right)$ by R0 were in the low range of the values recorded in previous reports [e.g., 10, 18, 22-23] due to the varied loading rates, immobilized anammox biomass, and packing ratios as well as reactor configurations and operations applied in the studies. However, it should be noted that the maximum nitrogen removal capacity of the reactor was not explored in this study, and it was deduced that the superiority of immobilized anammox biomass might be more significant at a higher nitrogen loading rate due to the high retention efficiency and stable growth environment of immobilization for anammox bacteria.

\section{Stoichiometric Characteristics of the Immobilized Anammox Reactor}

According to the anammox reaction, the theoretical stoichiometric ratio of removed $\mathrm{NO}_{2}^{-}-\mathrm{N}$ to $\mathrm{NH}_{4}{ }^{+}-\mathrm{N}$ and produced $\mathrm{NO}_{3}^{-}-\mathrm{N}$ to removed $\mathrm{NH}_{4}^{+}-\mathrm{N}$ was 1.32 and 0.26 , respectively [4]. In the current study, the ratio of removed $\mathrm{NO}_{2}^{-}-\mathrm{N}$ to $\mathrm{NH}_{4}^{+}-\mathrm{N}$ of the immobilized anammox reactor was close to the theoretical value from day 6 onward (Fig. 3a), indicating a successful start-up of anammox in the reactor. Then the ratio decreased below the theoretical value, ranging 1.01-1.32 with an average value of 1.15 , meaning more consumption of ammonium than nitrite. This might be a result of the ammonia oxidation process using DO in the influent outcompeting nitrite oxidation at a limited DO level [22, 24].

The ratio of produced $\mathrm{NO}_{3}^{-}-\mathrm{N}$ to removed $\mathrm{NH}_{4}^{+}-\mathrm{N}$ was largely lower than the theoretical value, which was probably due to the existence of the denitrification

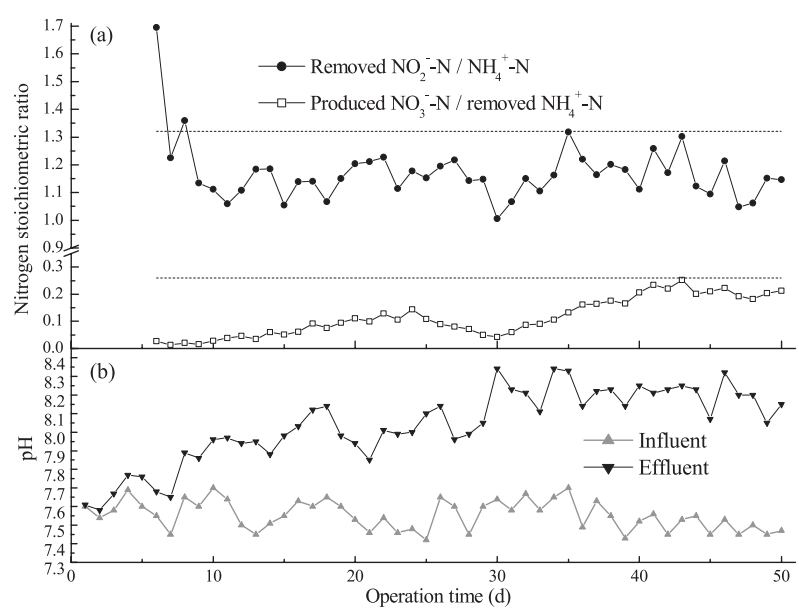

Fig. 3. Time courses of a) stoichiometric ratios of nitrogen conversions and $\mathrm{b}$ ) influent and effluent $\mathrm{pH}$ values of $\mathrm{R} 1$. 
process in the reactor utilizing the carbon source derived from the PVA-SA gel and slight degradation of the immobilized sludge. We deduced that denitrifiers coexisted with anammox bacteria in the seed anammox sludge [17]. This nitrate reduction is beneficial for TN removal in the reactor [24]. Then this ratio was close to the theoretical value from the day 40. By comparison, these two ratios were close to the values documented in other immobilized anammox reactors [7, 18, 22], suggesting the responsibility of anammox for nitrogen removal in R1.

In addition, another important parameter that can characterize anammox reaction and influence the metabolism of anammox bacteria, $\mathrm{pH}$, was determined during the experiment (Fig. 3b). Acidity can be consumed in anammox reaction, with the $\mathrm{pH}$ level in the reactor elevated $[4,21]$. The effluent $\mathrm{pH}$ value increased gradually after the experiment began, and was clearly higher than that of the influent - especially in operational phase 2, indicating intense anammox activity in the reactor. We detected that the $\mathrm{TN}$ volume removal rate of the reactor was positively correlated with the $\mathrm{pH}$ variation value between the effluent and influent $(\Delta \mathrm{pH})$ significantly $\left(r^{2}=0.80, p<0.01\right)$. The $\mathrm{pH}$ ranging $7.6-8.3$ during the experiment would have no influence on the anammox activity of the reactor due to the optimum $\mathrm{pH}$ for anammox bacteria being in the range 7.7-8.2 [3].

\section{Variations of Water Quality Characteristics in R1 during one Feeding Batch}

In order to understand the nitrogen removal process in the immobilized anammox reactor, temporal variations of water qualities during a 12-h HRT were determined through a batch test at the end of the continuous feeding experiment (on day 51), when a stable running state was achieved in the reactor. Fresh wastewater was refilled within 5 min after the treated wastewater was drained, and the water quality characteristics were measured at an interval of 1 h. Fig. 4 showed the temporal variations of $\mathrm{DO}$ concentration, $\mathrm{ORP}$, and $\mathrm{TN}$ removal efficiency of the reactor. It was observed that the DO content decreased sharply from $3.3 \mathrm{mg} \cdot \mathrm{L}^{-1}$ in the influent to $0.46 \mathrm{mg} \cdot \mathrm{L}^{-1}$ at hour 4 , which is under the tolerable level of anammox

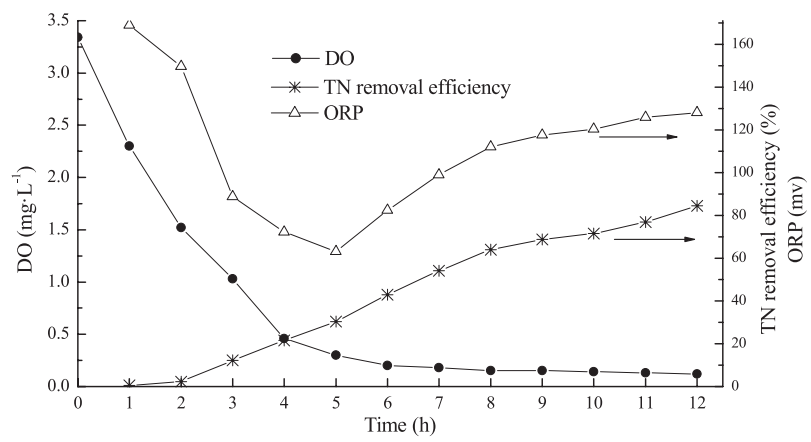

Fig. 4. Time courses of DO concentration, ORP, and TN removal efficiency of R1 with immobilized anammox sludge during one feeding batch after stable operation. bacteria [25], probably due to the presence of nitrification process as mentioned above. ORP also decreased from $169 \mathrm{mv}$ at hour 1 to $63.1 \mathrm{mv}$ at hour 5, which could primarily be attributed to the consumption of DO, which is significant for the creation of anaerobic conditions for anammox reaction inside the reactor. Then the ORP increased gradually to $128 \mathrm{mv}$ at hour 12 , along with the gradual increase of TN removal efficiency. ORP value was a good indicator for providing more detailed information on monitoring the performance and operational state of an anammox reactor [26]. It was reported that the anammox process could take place in an ORP range of 50-140 mv [24, 26-27]. TN removal did not occur until the second hour, probably due to the impact of high DO content, and it then increased gradually to $84.4 \%$ at hour 12 . HRT was a crucial operational parameter for nitrogen removal of the reactor - especially in the first $8 \mathrm{~h}$.

\section{Conclusion}

High nitrogen removal efficiency was achieved in this study in a bioreactor seeded with immobilized anammox sludge by PVA-SA gel after a short start-up period of 10 d. As compared with the reactor with anammox sludge inoculated directly, the immobilized anammox reactor performed significantly better and was stable in nitrogen removal, especially after the increase of loading rate, with the efficiency stabilized over $83.5 \%$ at a steady operational state. Nitrogen removal increased gradually with the HRT. It has the potential to apply immobilized anammox sludge entrapped by PVA-SA gel for quick establishment of an anammox reactor with stable and high-rate nitrogen removal.

\section{Acknowledgements}

This work was financially supported by grants of the National Natural Science Foundation of China (51408531), and the Major Science and Technology Program for Water Pollution Control and Treatment (2012ZX07302-002-11).

\section{References}

1. DONG W.Y., WANG H.J., LI W.G., YING W.C., GAN G.H., YANG Y. Effect of DO on simultaneous removal of carbon and nitrogen by a membrane aeration/filtration combined bioreactor. J membrane Sci. 344 (1), 219, 2009.

2. CHANG J., LU Y., CHEN J., WANG X., LUO T., LIU $H$. Simultaneous removals of nitrate and sulfate and the adverse effects of gravel-based biofilters with flower straws added as exogenous carbon source. Ecol. Eng. 95, 189, 2016.

3. STROUS M., VAN GERVEN E., ZHENG P., KUENEN J.G., JETTEN M.S.M. Ammonium removal from concentrated waste streams with the anaerobic ammonium oxidation (anammox) process in different reactor configurations. Water Res. 31 (8), 1955, 1997. 
4. STROUS M., HEIJNEN J.J., KUENEN J.G., JETTEN M.S.M. The sequencing batch reactor as a powerful tool for the study of slowly growing anaerobic ammoniumoxidizing microorganisms. Appl. Microbiol. Biotechnol. 50 (5), 589, 1998.

5. LACKNER S., GILBERT E.M., VLAEMINCK S.E., JOSS A., HORN H., VAN LOOSDRECHT M.C. Full-scale partial nitritation/anammox experiences - an application survey. Water Res. 55, 292, 2014.

6. JIN R., YANG G., YU J., ZHENG P. The inhibition of the Anammox process: a review. Chem. Eng. J. 197, 67, 2012.

7. ALI M., OSHIKI M., RATHNAYAKE L., ISHII S., SATOH H., OKABE S. Rapid and successful start-up of anammox process by immobilizing the minimal quantity of biomass in PVA-SA gel beads. Water Res. 79, 147, 2015.

8. HE S., NIU Q., MA H., ZHANG Y., LI Y.Y. The treatment performance and the bacteria preservation of Anammox: a review. Water Air Soil Pollut. 226 (5), 1, 2015.

9. CHEN J., JI Q., ZHENG P., CHEN T., WANG C., MAHMOOD Q. Floatation and control of granular sludge in a high-rate anammox reactor. Water Res. 44 (11), 3321, 2010.

10. ISAKA K., DATE Y., SUMINO T., TSUNEDA S. Ammonium removal performance of anaerobic ammoniumoxidizing bacteria immobilized in polyethylene glycol gel carrier. Appl. Microbiol. Biotechnol. 76 (6), 1457, 2007.

11. HSIA T.H., FENG Y.J., HO C.M., CHOU W.P., TSENG S.K. PVA-alginate immobilized cells for anaerobic ammonium oxidation (anammox) process. J. Ind. Microbiol. Biotechnol. 35 (7), 721, 2008.

12. QIAO S., TIAN T., DUAN X., ZHOU J., CHENG Y. Novel single-stage autotrophic nitrogen removal via coimmobilizing partial nitrifying and anammox biomass. Chem. Eng. J. 230, 19, 2013.

13. HERRERO M., STUCKEY D.C. Bioaugmentation and its application in wastewater treatment: a review. Chemosphere 140, 119, 2015.

14. GANI K.M., SINGH J., SINGH N.K., ALI M., ROSE V., KAZMI A.A. Nitrogen and carbon removal efficiency of a polyvinyl alcohol gel based moving bed biofilm reactor system. Water Sci. Tech. 73 (7), 1511, 2016.

15. WANG W., DING Y., WANG Y., SONG X., AMBROSE R.F., ULLMAN J.L., WINFREY B.K., WANG J., GONG J. Treatment of rich ammonia nitrogen wastewater with polyvinyl alcohol immobilized nitrifier biofortified constructed wetlands. Ecol. Eng. 94, 7, 2016.
16. ZHU G.L., HU Y.Y., WANG Q.R. Nitrogen removal performance of anaerobic ammonia oxidation co-culture immobilized in different gel carriers. Water Sci. Tech. 59 (12), $2379,2009$.

17. LU Y., MA L., MA L., SHAN B., CHANG J. Improvement of start-up and nitrogen removal of anammox process in reactors inoculated with conventional activated sludge using biofilm carrier materials. Environ. Technol. DOI: 10.1080/09593330.2017.1294624, 2017.

18. QUAN L.M., HIRA D., FUJII T., FURUKAWA K. Reject water treatment by improvement of whole cell anammox entrapment using polyvinyl alcohol/alginate gel. Biodegradation 22 (6), 1155, 2011.

19. APHA. Standard Methods for the Examination of Water and Wastewater. 20th ed. American Public Health Association, Washington, DC, 1998.

20. ISAKA K., DATE Y., SUMINO T., YOSHIE S., TSUNEDA $S$. Growth characteristic of anaerobic ammonium-oxidizing bacteria in an anaerobic biological filtrated reactor. Appl. Microbiol. Biotechnol. 70 (1), 47, 2006.

21. TANG C.J., ZHENG P., MAHMOOD Q., CHEN J.W. Start-up and inhibition analysis of the Anammox process seeded with anaerobic granular sludge. J. Ind. Microbiol. Biotechnol. 36 (8), 1093, 2009.

22. BAE H., CHOI M., LEE C., CHUNG Y.C., YOO Y.J., LEE S. Enrichment of ANAMMOX bacteria from conventional activated sludge entrapped in poly (vinyl alcohol)/sodium alginate gel. Chem. Eng. J. 281, 531, 2015.

23. MAGRÍ A., VANOTTI M.B., SZÖGI A.A. Anammox sludge immobilized in polyvinyl alcohol (PVA) cryogel carriers. Bioresour. Technol. 114, 231, 2012.

24. ANJALI G., SABUMON P.C. Unprecedented development of anammox in presence of organic carbon using seed biomass from a tannery Common Effluent Treatment Plant (CETP). Bioresour. Technol. 153, 30, 2014

25. JENSEN M.M., KUYPERS M.M., GAUTE L., THAMDRUP B. Rates and regulation of anaerobic ammonium oxidation and denitrification in the Black Sea. Limnol. Oceanogr. 53 (1), 23, 2008.

26. LACKNER S., LINDENBLATT C., HORN H. 'Swinging ORP' as operation strategy for stable reject water treatment by nitritation - anammox in sequencing batch reactors. Chem. Eng. J. 180, 190, 2012.

27. SUNEETHI S., JOSEPH K. Batch culture enrichment of ANAMMOX populations from anaerobic and aerobic seed cultures. Bioresour. Technol. 102 (2), 585, 2011. 